Dhaka Univ. J. Biol. Sci. 31(1): 67-78, 2022 (January) DOI: https://doi.org/10.3329/dujbs.v31i1.57917

\title{
BREEDING BIOLOGY OF NORTHERN RIVER TERRAPIN BATAGUR BASKA IN CAPTIVITY IN BANGLADESH
}

\author{
Ebtisamul Zannat Mim, Mohammad Firoj Jaman, AGJ Morshed", \\ Md Mahabub Alam* and NasRin AKTer Bristy \\ Department of Zoology, University of Dhaka, Dhaka-1000, Bangladesh
}
Key words: Batagur baska, Reproduction, Captive breeding, Project Batagur, Ecological extinction, Bangladesh.

\begin{abstract}
Northern River Terrapin, Batagur baska, is an ecologically extinct species in Bangladesh. The 'Project Batagur' has undertaken some important initiatives to resuscitate the nearly deceased population through captive breeding at Bhawal National Park, Gazipur, Bangladesh. We conducted a study on breeding biology of B. baska from May 2016 to June 2017 in the project site. Four adult females and three adult males comprised breeding pair in the study site. Male Batagur baska developed black colouration on head and neck, with rich crimson on dorsal portion of the neck during breeding season. During our study, we observed paired basking behaviour rather courtship and parental care. We found three nests from mid-March to first week of April. Females laid eggs at night and a total of 67 eggs were extracted from three nests; eggs were elliptical and whitish in colour. Clutch size varied from 18 to 28 eggs. There was significant positive correlation between clutch size and nest diameter $(p=0.03)$. The relationship was also positive and significant between egg weight and diameter $(\mathrm{p}=0.01)$. The size of the egg was not related with the size of breeding females $(r=0.143)$.Average incubation period was $(68.26 \pm 5.23)$ days and there was significant negative relationship with temperature $(\mathrm{p}=0.000)$, clutch size $(\mathrm{p}=0.001)$, and hatching success $(p=0.004)$. Hatching success was also negatively co-related with temperature $(\mathrm{p}=0.001)$. Hatching started in May and ended in the first week of June 2017 with mean hatching success of $91 \%$. Simple linear regression showed positive relationship between egg length and hatchlings' carapace length, plastron length, and height. We also found positive relationship between egg diameter and hatchlings weight, and carapace width. This study can be used as a protocol for captive breeding and rearing activities of threatened chelonians around the world.
\end{abstract}

\section{Introduction}

The genus Batagur has three species in Bangladesh, Batagur baska, Batagur kachuga, and Batagur dhongoka ${ }^{(1)}$. Batagur baska has a distribution that includes India, Bangladesh, and Myanmar (2-6). During the $19^{\text {th }}$ and $20^{\text {th }}$ centuries, this species was abundant from the

*Author for correspondence: <mahabub.zoo@du.ac.bd>.1Project-Batagur, Vienna Zoo, Maxingstraße13b, 1130 Vienna, Austria. 
Hugli river of India to the Ayeyarwady and the Bago Rivers of Myanmar(2-3,5). In Bangladesh, Northern River Terrapin is known to occur in large rivers and estuaries in the coastal districts of Noakhali, Barisal, and Khulna ${ }^{(7)}$. The global wild population of Batagur baska has decreased over the last two centuries with less than 100 mature remaining individuals(4). Population of this species have also been decimated from the wild in Bangladesh $(5,6,8)$. The causes of decline include removal of mangrove forests and sand mining(5,9-11), exploitation for eggs and adults, habitat loss, degradation and fragmentation ${ }^{(4,6,10-12)}$. Illegal turtle trade ${ }^{(4,13)}$, incidental capture in fishing nets and traps, accidental death by collision with motor-boats, watercrafts, loss of nesting beaches, destructive fishing practices and unseasonal floods ${ }^{(10)}$ are also responsible for the decline. These activities pose serious threats to this species globally including Bangladesh ${ }^{(4,5,10)}$. $B$. baska is now globally Critically Endangered $(\mathrm{CR})^{(4,5)}$, and regarded as one of the tropical Asia's most threatened chelonians ${ }^{(14,15)}$. It is also listed in the CITES Appendix I, where commercial trade of the species is completely prohibited ${ }^{(4)}$.

Wild populations of Northern River Terrapin have been decimated to such an extent that the species is considered as ecologically extinct(5-6). Spitzweg et al.(16) also reported that wild population experienced a grave decline long time ago confirmed by genetic studies of this species. Thus, the species is unable to survive without major ex situ conservation efforts ${ }^{(6)}$. First successful captive breeding initiative of $B$. baska was taken at Bronx Zoo in 1990(17). In 2010, the first two captive-bred batches of juveniles hatched under a project at Vienna Zoo, Austria. This breakthrough presented an opening to call for attention to this Critically Endangered species(6). In Bangladesh, 'Project Batagur' initiated with combined efforts with Vienna Zoo, Austria to promote ex situ conservation project in Bhawal National Park. In between 2012 and 2019, there were 265 juveniles hatched and fostered in captivity in Bangladesh.

To date, reproductive activities of $B$. baska are very little known in literature. The study aims to investigate breeding behaviour and breeding biology of the species in captivity. The study also provides the baseline information and enhances scientific knowledge that will provide insights for future conservation efforts in Bangladesh.

\section{Materials and Methods}

Study area: We conducted this study at 'Project-Batagur' site in Bhawal National Park

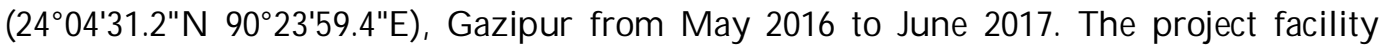
includes a large non-breeding pond, a small breeding pond, and seven rearing tanks for hatchlings of Batagur baska. The rectangular non-breeding pond $(48.786 \mathrm{~m} \times 24.384 \mathrm{~m})$ is accommodated with a sandy beach. The sandy beach has two iron cages with similar measurement $(1.83 \mathrm{~m} \times 1.83 \mathrm{~m})$. Slope of the large pond is straight with $10.3 \mathrm{~m}$ in length. The peak height of the slope was $1.13 \mathrm{~m}$ from the water level. On the other hand, size of small breeding pond is $24.38 \mathrm{~m} \times 18.3 \mathrm{~m}$ in measurement. This pond has $11.9 \mathrm{~m}$ long 
sandy beach. The steepness of beach is gradual and slightly convex. The half-circle beach is encompassed by $0.69 \mathrm{~m}$ tall brick wall. The vertical length of the beach is $2.13 \mathrm{~m}$ from the water level. The water level of both ponds varies depending on the season. Water level goes down to $1.4 \mathrm{~m}$ during winter season. Seven well-constructed rearing tanks are placed linearly beside the non-breading pond for rearing hatchlings and juveniles. The larger tanks with similar sizes $(4.3 \mathrm{~m} \times 3.05 \mathrm{~m} \times 0.9 \mathrm{~m})$ while the smaller tanks also have the similar size of each $(1.8 \mathrm{~m} \times 1.8 \mathrm{~m} \times 0.9 \mathrm{~m})$. The water level of both larger and smaller tanks was $0.8 \mathrm{~m}$.

Data collection: Data on breeding activities were collected twice a week during breeding season (September 2016 - June 2017), and once a week during non-breeding season (July-August 2016) that allowed us to compare turtle's breeding behaviour between these two seasons. There were four adult females and three adult males of $B$. baska, which comprised a breeding group in the project site. These individuals were kept in a very organized housing system and well-maintained breeding ponds. During the study, we confirmed identification of mature females by following Bhupathy(18). Mature females in the study had mean carapace length (CL) of $500 \mathrm{~mm}$, Carapace width (CW) of $400 \mathrm{~mm}$, and body mass was $17 \mathrm{~kg}$. We also followed Rashid \& Swingland ${ }^{(19)}$ to confirm adult males, that had CL of $421 \mathrm{~mm}$, CW of $214 \mathrm{~mm}$, plastron length (PL) of $378 \mathrm{~mm}$, height $(\mathrm{H})$ of $161 \mathrm{~mm}$, and body weight $8.87 \mathrm{~kg}$. We observed the ponds every morning carefully to trace the females' footprints to find the nesting places as well as any nest markings. The time and date of breeding activities were documented in order to determine breeding season in captivity. Breeding behaviour such as courtship, breeding colouration, paired basking, nest making and egg laying activities were observed and documented. We spent five to six days each month in the project site. In our absence, the caretaker of the project recorded breeding data according to our prescribed instructions for the rest of the days and we collected it afterward. When we found any nest, the layers of sand on the nest were removed carefully, and eggs were collected by bare hand. Clutch size was calculated by enumerating the eggs laid in nests. Weight, length, and diameter of eggs were measured immediately after the collection. The eggs from the natural nest were kept in anti-ant plastic boxes with similar measurements $(57.5 \mathrm{~cm} \times$ $37.5 \mathrm{~cm} \times 22.5 \mathrm{~cm}$ ) provided by the project authority following Weissenbacher et al.(6). A sand layer was made inside the boxes and the eggs were kept in two to three rows above the layer and then covered again by another sand layer. The boxes were well facilitated to pass air and moisture. A digital Hobo thermometer was attached to the boxes to record temperature. The incubation period was monitored in the anti-ant boxes fitted well under the sand. The incubation period was calculated from the day of keeping the eggs in the boxes. Both nest and boxes were protected by an iron cage to keep it safe from predators such as Varanus spp. and Herpestes spp.(6). Hatching success was calculated by enumerating the number of hatchlings in relation to the eggs laid per clutch. 
Morphometric data of adult B. baska, eggs, and hatchlings were recorded in log book during field visits. The eggs, hatchlings, and adults were weighted by using digital weight machine. Slide calipers were used to measure egg length (EL), egg diameter (ED), as well as CL, CW, PL, H of hatchling. The size of adults, nest depth, diameter, and nest distance from water level were measured using measuring tape (about $15.5 \mathrm{~m} \mathrm{long}$ ). Egg shape was defined by the ratio of its length, and diameter. The ratio of spherical eggs varied from 1.00 to 1.10 , elliptical eggs between 1.11 and 1.99, and oblong eggs had at least twice of its diameter ${ }^{(20)}$. The hatchlings were transferred carefully into the rearing tanks immediately after hatching out. Hatching success was calculated by considering the total number of eggs laid, the young hatched and rearing of hatchlings.

Data were processed in computer software in combination with Statistical Package for Social Science (SPSS version, 17.0), and MS Excel. We performed simple linear regression and correlation to assess the relationship between breeding parameters. Significance was tested at $\mathrm{p}<0.05$.

\section{Results and Discussion}

Observation of breeding behaviour: Breeding behaviour of B. baska was started in early September. Head colouration of breeding male was observed first time in September 2016 and fainted in February 2017. In breeding male, B. baska showed black colouration on head and neck, dorsal portion of the neck was also rich crimson in colour ${ }^{(5,16,21)}$. These seasonal colourations were shown by males presumably associated with breeding ${ }^{(22)}$. Females didn't show any breeding colouration due to difficulty to recognize their less colourful nature during breeding season ${ }^{(5,21)}$. B. baska also showed the highest breeding activities due to breeding season that match with the previous study done by Sadat ${ }^{(23)}$. We observed head swaying and throat pumping behaviour rather courtship to perform breeding activities(17). Paired basking was observed in breeding pond about a month before the nest building and ended a week before laying eggs. Female turtles were found basking just behind the male.

Nesting sites, nest building and egg laying: Three circular nests were made on sandy bank with the help of head and sharp claws of forelimbs. We found first nest on 13 March, 2017; the second nest on 20 March, 2017 and the third nest on 02 April, 2017. The distance of the first, second and third nests were $640 \mathrm{~cm}, 716 \mathrm{~cm}$ and $692 \mathrm{~cm}$ (mean 682.67 $\pm 38.85 \mathrm{~cm}$ ), respectively, from the water level. Batagur baska builds nest on island shores, beaches of the river mouth and along the coastlines $(5,22,24)$. Our result also corroborated previous studies suggesting that $B$. baska made nests at the end of January through late March (7,18,24-26). Weissenbacher et al.(6) also stated that $B$. baska nested in spring during mid-February to mid-April. The depth of the nests was $28 \pm 3 \mathrm{~cm}$ (range $25-31 \mathrm{~cm}$ ) and diameter was $46 \pm 4 \mathrm{~cm}$ (range $42-50 \mathrm{~cm}$ ) from the land surface (Table 1). Nest depth and diameter of $B$. baska varied due to the different sizes of eggs laid in the nests. The nests 
were covered by sand after the female laying egg. Female turtles laid only one clutch of eggs in one breeding season between March and mid-April 2017. Eggs were laid at night and we found a total of 67 eggs from three nests. It could not be confirmed whether female laid eggs probably due to nest-building or egg-laying behaviour of B. baska in dark ${ }^{(5,24)}$. The clutch size was $22.33 \pm 5.13$ eggs (range 18 - 28 eggs) (Table 1 ).

Table 1. Measurements of nests $(n=3)$ and eggs $(n=67)$ of Batagur baska from May 2016 to June 2017 in captivity in Bangladesh.

\begin{tabular}{lccccccccc}
\hline \multirow{2}{*}{$\begin{array}{c}\text { Nest } \\
\text { no. }\end{array}$} & $\begin{array}{c}\text { Nest } \\
\text { depth }\end{array}$ & $\begin{array}{c}\text { Nest } \\
\text { diam. } \\
(\mathrm{cm})\end{array}$ & $\begin{array}{c}\text { Clutch } \\
(\mathrm{cm})\end{array}$ & size & \multicolumn{2}{c}{$\begin{array}{c}\text { Egg weight } \\
(\mathrm{g})\end{array}$} & \multicolumn{2}{c}{$\begin{array}{c}\text { Egg length } \\
(\mathrm{mm})\end{array}$} & \multicolumn{2}{c}{$\begin{array}{c}\text { Egg diameter } \\
(\mathrm{mm})\end{array}$} \\
\cline { 5 - 11 } & & & & Range & Mean \pm SD & Range & Mean \pm SD & Range & Mean \pm SD \\
\hline First & 28 & 46 & 21 & $75.15-84.2$ & $78.99 \pm 2.05$ & $67.9-78.59$ & $71.29 \pm 2.44$ & $43.29-44.86$ & $44.17 \pm 0.37$ \\
Second & 31 & 50 & 28 & $67.9-77.5$ & $71.32 \pm 2.06$ & $68.65-76.76$ & $73.79 \pm 2.05$ & $38.57-42.13$ & $40.97 \pm 0.68$ \\
Third & 25 & 42 & 18 & $64-78$ & $69.44 \pm 3.27$ & $56-76$ & $67.88 \pm 4.45$ & $39-44$ & $41.05 \pm 1.16$ \\
\hline
\end{tabular}

The relationship between clutch size and nest diameter was significantly correlated $(\mathrm{r}$ $=0.974, \mathrm{t}=-6.30, \mathrm{df}=4, \mathrm{p}=0.03)$ and insignificantly correlated with nest depth $(\mathrm{r}=0.974$, $\mathrm{t}=-1.65, \mathrm{df}=4, \mathrm{p}=0.17)$. The greater the clutch sizes the deeper and wider the nest was. Simple linear regression also showed the positive relationship between clutch size and nest diameter $\left(Y=29.038+0.7595 \times\right.$ egg weight, $\left.R^{2}=0.949\right)$ and the nest depth $(Y=15.278$ $+0.5696 \times$ egg weight, $R^{2}=0.949$ ) (Fig. 1).

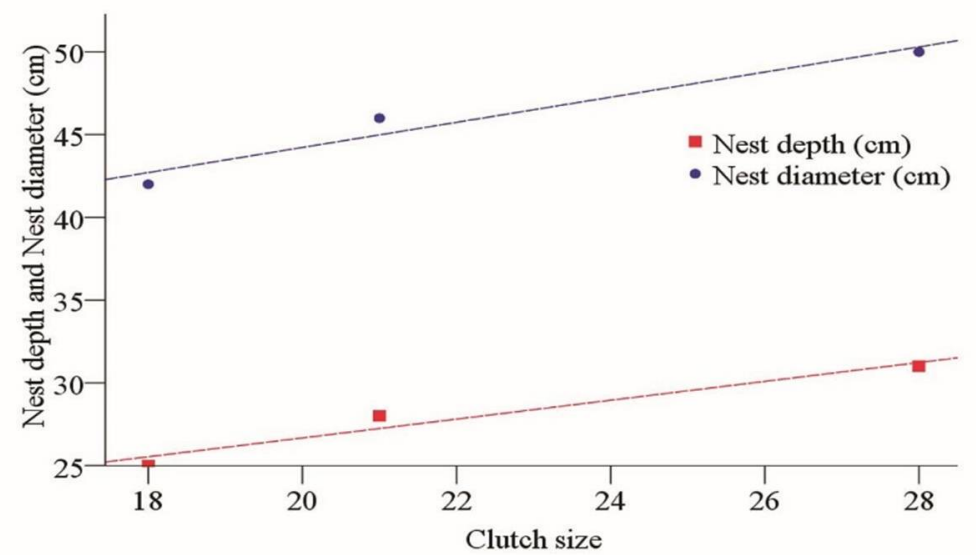

Fig. 1. Clutch size in relation to the depth and diameter of the nest of Batagur baska.

Our observed clutch size was almost similar with the clutch size 10 - 30 in captive population of $B$. baska of Bangladesh ${ }^{(6,7,24)}$. Weissenbacher et al.(6) also recorded clutch size of 21 - 24 eggs at the Vienna Zoo, Austria. The number of observed eggs in a clutch was 
larger than the average 50 eggs in a clutch reported by Daniel(25) while Duli(22) stated 26 eggs, and Moll(27) described the clutch size 19 - 48 eggs. Variation in egg size and shape may be associated with clutch size and female anatomy ${ }^{(28,29)}$.

Shape, colour and measurements of eggs: Eggs shape of Batagur baska was elliptical with an average EL and ED ratio 1.68. The shell was delicate and fine with whitish in colour.

The adult females had mean weight of $20.29 \mathrm{~kg}$, CL of $477.5 \mathrm{~mm}, \mathrm{CW}$ of $396.2 \mathrm{~mm}$ and $\mathrm{H}$ of $218.7 \mathrm{~mm}$. The weight, length and diameter of individual eggs was $73.21 \pm 4.66 \mathrm{~g}$ (range $64-84.2 \mathrm{~g}, \mathrm{n}=67$ ), $71.42 \pm 3.80 \mathrm{~mm}$ (range 56-78.59 mm) and $41.99 \pm 1.66 \mathrm{~mm}$ (range $38.57-44.86 \mathrm{~mm}$ ), respectively. The size of the egg (EL) was not related with the size of breeding females (female CL) $(\mathrm{r}=0.143)$. We also found variation of weight, length and diameter of eggs in each clutch of three nests (Table 1). The relationship between the eggs weight and ED was positively significantly correlated $(r=0.978, n=67, t=10.043$, df $=4, \mathrm{p}=0.01)$. There was no relationship between the egg weight and EL $(\mathrm{r}=0.272, \mathrm{t}=$ $0.668, \mathrm{df}=4, \mathrm{p}=0.540$ ). The relationship between egg weight and diameter maintained linearity. Simple linear regression showed the positive relationship between egg weight and ED $\left(Y=16.215+0.353 \times\right.$ egg weight, $\left.R^{2}=0.957\right)$. There was no relation between egg weight and EL $\left(Y=59.30+0.160 \times\right.$ egg weight, $\left.R^{2}=0.074\right)($ Fig. 2$)$. Variation of EL and ED of $B$. baska was observed due to the different sized egg in nests. For instance, B. baska had EL of $68-75 \mathrm{~mm}$, ED of $39-45 \mathrm{~mm}$ with mean weight $69-80 \mathrm{~g}^{(24,27,30)}$. These previous studies support our findings.

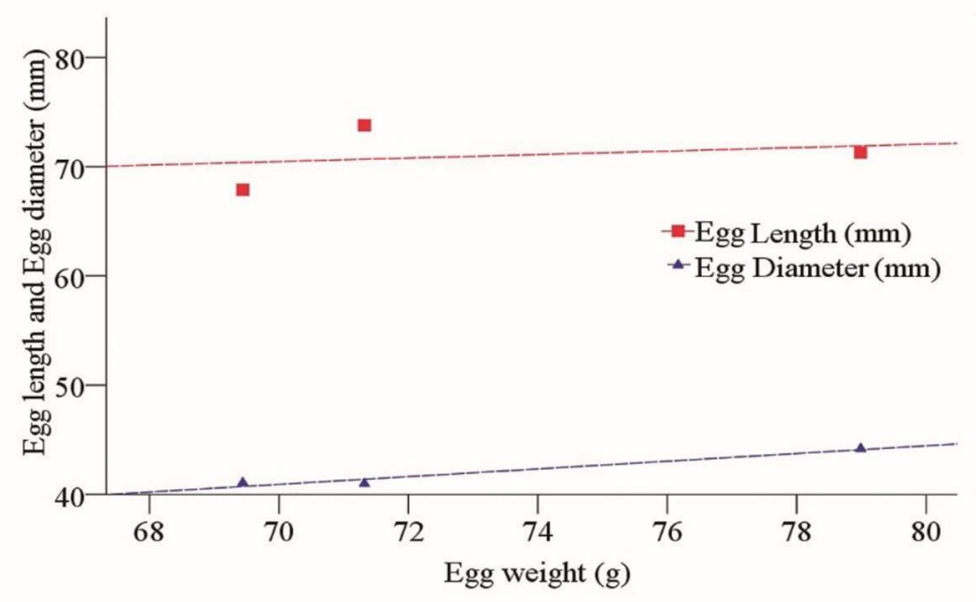

Fig. 2. Relationship between egg diameter and egg length with egg weight Batagur baska.

Incubation and temperature of nests: The mean incubation period was $68.26 \pm 5.23$ days (range 57 - 80 days). The variation of incubation period for first clutch was $75.63 \pm 1.46$ days (range 74 - 80 days), $65.42 \pm 0.85$ days (range 65 - 68 days), and $64.12 \pm 2.15$ days (range 57 - 65 days) for second and third clutch, respectively. Egg incubation period of $B$. 
baska was previously documented 57 - 74 days in Bangladesh (7). Maxwell(24) also recorded that the average egg incubation period was 70 days while Weissenbacher et al.(6) reported 59 - 77 days for this species in the same country. The number of days required for hatching revealed the similar result with our study. The mean temperature of three boxes was $29.73 \pm 1.88^{\circ} \mathrm{C}$ (range $23.97-32.7^{\circ} \mathrm{C}$ ). The temperature of first clutch was $29.04 \pm 2.2^{\circ} \mathrm{C}$ (range $23.97-32^{\circ} \mathrm{C}$ ), second clutch $29.66 \pm 1.55^{\circ} \mathrm{C}$ (range $24.5-32.04{ }^{\circ} \mathrm{C}$ ), and third clutch $30.55 \pm 1.45^{\circ} \mathrm{C}$ (range $25.53-32.7^{\circ} \mathrm{C}$ ). We found high temperature shortened incubation periods. Eggs of the first clutch took longer period with minimum average temperature of $29.04^{\circ} \mathrm{C}$. We found significant negative correlation between the incubation period with the temperature $(r=-0.866)$, clutch size $(r=-0.123)$, and hatching success $(r=-0.011)$ (Table 2). The relation between temperature and hatching success was also negative, and significant $(\mathrm{r}=-0.490, \mathrm{t}=-49.41, \mathrm{df}=4, \mathrm{p}=0.000)$. We also performed simple linear regression between the incubation with the temperature, clutch size, and hatching success (Table 2, Fig. 3). Variation in temperature might influence the egg incubation of B. bask $a^{(17,31)}$. We found the mean incubation temperature $29.73^{\circ} \mathrm{C}$, which corroborated the previous recorded temperature $23-33^{\circ} \mathrm{C}(7,31)$.

Table 2. Relationship between incubation periods with other reproductive parameters of Batagur baska from May 2016 to June 2017 in captivity in Bangladesh.

\begin{tabular}{llccccccc}
\hline \multirow{2}{*}{ Parameters } & $\mathrm{r}$ value & $\mathrm{t}$ - statistics & $\mathrm{df}$ & $\mathrm{p}$ & & \multicolumn{2}{c}{ Simple linear regression } \\
\cline { 7 - 9 } & & & (calculated) & & value & $R^{2}$ & Regression equation \\
\hline $\begin{array}{l}\text { Incubation } \\
\text { period }\end{array}$ & Temperature & -0.866 & 10.541 & 4 & 0.000 & 0.75 & $36.883-0.104 \times$ incubation period \\
& Clutch size & -0.123 & 9.814 & 4 & 0.001 & 0.015 & $29.201-0.100 \times$ incubation period \\
& Hatching success & -0.011 & -5.855 & 4 & 0.004 & 0 & $90.984-0.004 \times$ incubation period \\
\hline
\end{tabular}

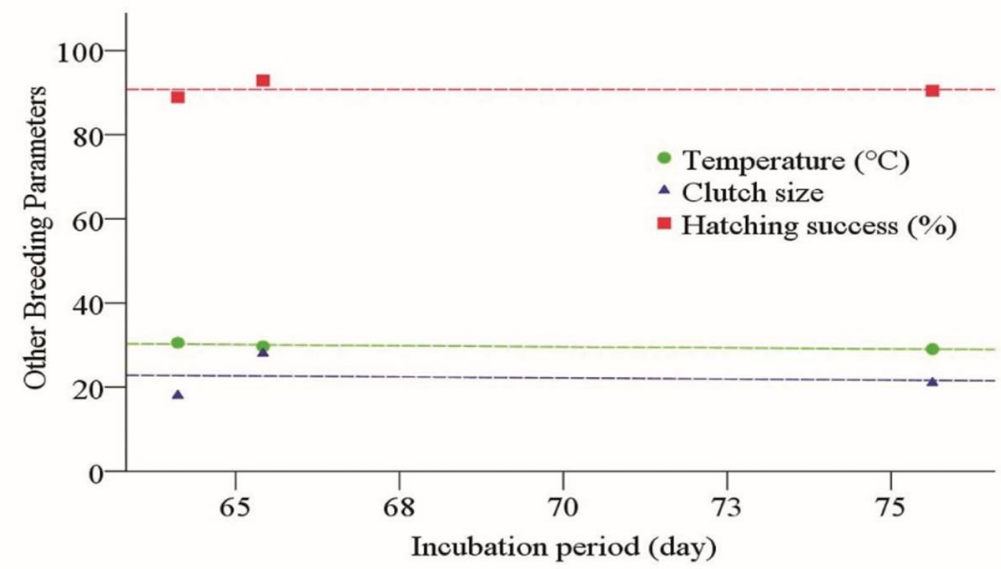

Fig. 3. Relationship between incubation periods with other breeding parameters Batagur baska. 
Hatching time, hatching and breeding success: Hatching started in May and ended in June, 2017. The eggs of both first and second clutches took four days to hatch completely. When hatching started, all the eggs of the third clutch completed hatching within 9 days. A total of 61 healthy hatchlings emerged out of 67 eggs from three artificial boxes, and hatching success was 91\%. Two eggs from each box totaling six among the 67 eggs were not developed for unknown reason. Hatching success was 19 (90.48\%) for first clutch, 26 $(92.86 \%)$ and $16(88.89 \%)$ for second and third clutch, respectively (Table 3). Hatchlings hatched out independently to the sand surface after breaking egg shell from the boxes. We did not find death of any hatchlings during our study period.

Table 3. Clutch size, hatching time and hatching success rate of Batagur baska from May 2016 to June 2017 in captivity in Bangladesh.

\begin{tabular}{lcccccc}
\hline $\begin{array}{c}\text { Nest } \\
\text { no. }\end{array}$ & $\begin{array}{c}\text { Clutch } \\
\text { size }\end{array}$ & $\begin{array}{c}\text { Mean incubation } \\
\text { period (day) }\end{array}$ & $\begin{array}{c}\text { Mean temp. } \\
\left({ }^{\circ} \mathrm{C}\right)\end{array}$ & Hatching time & $\begin{array}{c}\text { Hatchlings } \\
\text { number }\end{array}$ & $\begin{array}{c}\text { Hatching } \\
\text { success }(\%)\end{array}$ \\
\hline First & 21 & 75.63 & 29.04 & 25-28 May 2017 & 19 & 90.48 \\
Second & 28 & 65.42 & 29.66 & 23-26 May 2017 & 26 & 92.86 \\
Third & 18 & 64.12 & 30.55 & 28 May-05 June 2017 & 16 & 88.89 \\
\hline
\end{tabular}

The hatching success was $91 \%$ in the present study higher than $40 \%$ reported by Sanyal and Seth(26) and matched accurately with previous hatching success $91 \%$ (7). Congenial environment with constant nursing in the project site might contributed to the higher hatching success ${ }^{(7)}$. Furthermore, the eggs were kept in the plastic boxes, which provided strong protections from the predators especially red ants, Varanus spp. and Herpestes spp. ${ }^{(6)}$, consequently contributed to the higher hatching success.

Hatchlings growth measurement: Weight, CL, CW, PL and $\mathrm{H}$ of all hatchlings were measured after hatching out from the nests. Hatchlings weight was $49.16 \pm 1.38 \mathrm{~g}$ (range $48-52 \mathrm{~g}, \mathrm{n}=61$ ), CL was $62.61 \pm 0.98 \mathrm{~mm}$ (range $61-64 \mathrm{~mm}$ ), CW $59.79 \pm 1.75 \mathrm{~mm}$ (range 57 - $62 \mathrm{~mm}$ ), PL $58.05 \pm 1.18 \mathrm{~mm}$ (range $57-61 \mathrm{~mm}$ ), and $\mathrm{H}$ was $27.21 \pm 1.23 \mathrm{~mm}$ (range $24-29 \mathrm{~mm}$ ) for first box; whereas, the second box had hatchlings weight $46.54 \pm 1.65 \mathrm{~g}$ (range 44 - $50 \mathrm{~g}$ ), CL $62 \pm 1.17 \mathrm{~mm}$ (range 60 - $64 \mathrm{~mm}$ ), CW $56.77 \pm 3.28 \mathrm{~mm}$ (range $49-65$ $\mathrm{mm}$ ), PL $57.42 \pm 1.24 \mathrm{~mm}$ (range $56-60 \mathrm{~mm}$ ); and H $27.38 \pm 1.17 \mathrm{~mm}$ (range $25-30 \mathrm{~mm}$ ); in the third box hatchlings weight was $43.88 \pm 1.54 \mathrm{~g}$ (range $40-46 \mathrm{~g}$ ), CL $56.19 \pm 4.44 \mathrm{~mm}$ (range 51-63 mm), CW $54.31 \pm 4.19 \mathrm{~mm}$ (range 47 - $62 \mathrm{~mm}$ ), PL $54.31 \pm 4.19 \mathrm{~mm}$ (range 39 - $57 \mathrm{~mm}$ ), and $\mathrm{H}$ was $26.19 \pm 0.75 \mathrm{~mm}$ (range $25-27 \mathrm{~mm}$ ).

When the hatchlings weight, CL, CW, PL and $\mathrm{H}$ were examined via regression in relation to EL, there were positive relationship for CL $\left(R^{2}=0.999\right), \mathrm{PL}\left(R^{2}=0.686\right)$ and $\mathrm{H}$ $\left(R^{2}=0.910\right)$. No relationship was observed between hatchlings weight and CW (Table 4, Fig. 4). Among the growth measurements, only CL showed significant relationship ( $\mathrm{p}=$ 0.023) with EL (Table 4). 


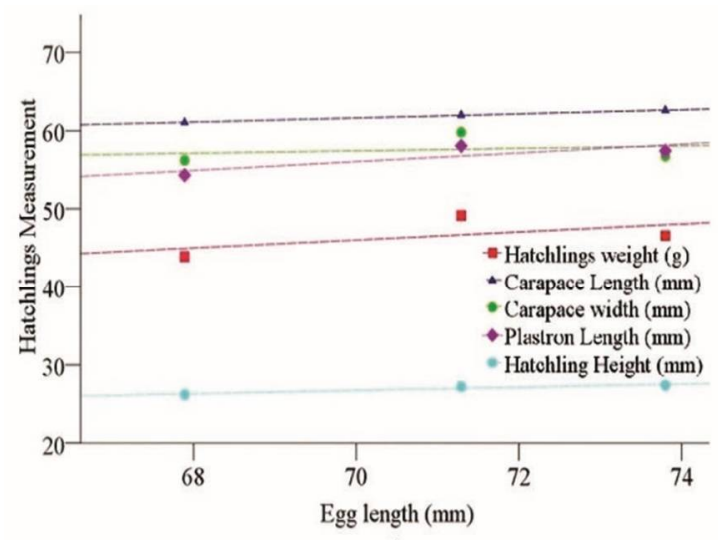

A

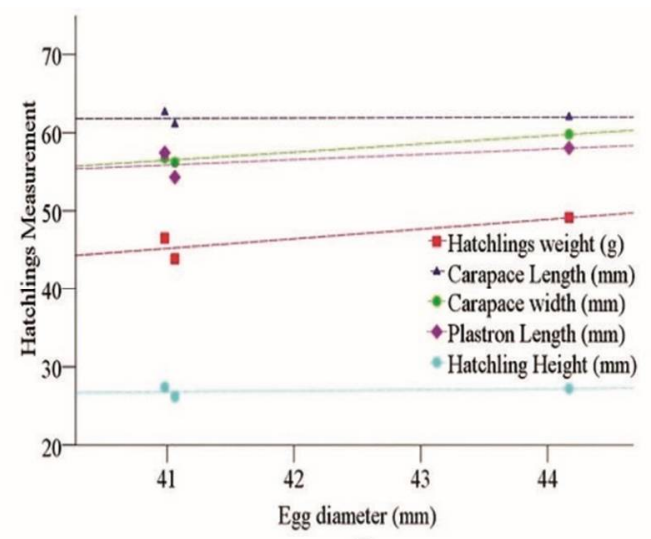

B

Fig. 4. Hatchlings growth in relation to egg size. (A) Egg length and (B) Egg diameter of Batagur baska.

Table 4. Regression analysis shows the relationship between EL and ED with hatchlings growth measurements Batagur baska from May 2016 to June 2017 in captivity in Bangladesh.

\begin{tabular}{|c|c|c|c|c|}
\hline & \multirow{2}{*}{$\begin{array}{l}\text { Hatchlings } \\
\text { growth }\end{array}$} & \multicolumn{2}{|c|}{ Simple linear regression } & \multirow[t]{2}{*}{$\mathrm{p}$ value } \\
\hline & & $R^{2}$ & Regression equation & \\
\hline \multirow[t]{5}{*}{ Egg length } & Weight & 0.333 & $10.085+0.513 \times$ egg length & 0.609 \\
\hline & $\mathrm{CL}$ & 0.999 & $43.213+0.263 \times$ egg length & 0.023 \\
\hline & $\mathrm{CW}$ & 0.055 & $46.707+0.153 \times$ egg length & 0.849 \\
\hline & PL & 0.686 & $16.900+0.559 \times \mathrm{egg}$ length & 0.379 \\
\hline & $\mathrm{H}$ & 0.910 & $12.230+0.207 \times$ egg length & 0.194 \\
\hline \multirow[t]{5}{*}{ Egg diameter } & Weight & 0.727 & $-5.526+1.237 \times$ egg diameter & 0.350 \\
\hline & $\mathrm{CL}$ & 0.010 & $60.082+0.043 \times$ egg diameter & 0.936 \\
\hline & $\mathrm{CW}$ & 0.971 & $13.545+1.047 \times$ egg diameter & 0.110 \\
\hline & PL & 0.376 & $28.216+0.675 \times$ egg diameter & 0.580 \\
\hline & $\mathrm{H}$ & 0.130 & $21.556+0.128 \times$ egg diameter & 0.765 \\
\hline
\end{tabular}

We also performed regression to assess the weight, CL, CW, PL, and $\mathrm{H}$ of hatchlings with ED (Fig. 4). We found positive relation only for hatchlings weight $\left(R^{2}=0.727\right)$ and CW $\left(R^{2}=0.971\right)$. The relationship was not significant for all growth measurements of hatchlings in relation to ED (Table 4). The weight of the eggs showed strong and positive relationship $(\mathrm{r}=0.94, \mathrm{t}=8.11, \mathrm{df}=4, \mathrm{p}=0.001)$ with hatchlings weight. We found that heavier and larger hatchlings came out from heavier and larger eggs ${ }^{(7)}$. When egg size was small, the hatchlings size was also shortened and became lighter in weight. Sanyal and Seth ${ }^{(26)}$ reported that smaller eggs produced lighter hatchling of $45 \mathrm{~g}$ which is almost similar to hatchlings weight of $49.16 \mathrm{~g}$ with the present study. 
In conclusion, northern River Terrapin is considered as ecologically extinct species due to very low number of individual in Bangladesh ${ }^{(5,6)}$. It is unable to survive without stringent in situ and $e x$ situ conservation efforts. The results of our study summarize breeding season and reproductive behaviour like nest building, egg laying, and incubation; which can be used as a protocol for wide ranging captive breeding and rearing activities of threatened chelonians elsewhere in the world. Furthermore, we found higher hatching success, and healthy hatchling in our study. This information might be helpful and provide a hope to reintroduce this species in nature. Considering their threatened status, we emphasize more researches on various ecological and conservation aspects of this species across sits distribution range.

\section{Acknowledgments}

We sincerely thank Bangladesh Forest Department (BFD), and board director of "Project Batagur" allowed us to conduct the survey in the center. We appreciated the support from International Union for Conservation of Nature (IUCN) Bangladesh, and Prokriti O Jibon Foundation (POJF) during the survey.

\section{References}

1. Rhodin AGJ, JB Iversion, R Bour, U Fritz, A Georges, HB Shaffer and PP van Dijk 2017. Turtles of the World: Annotated Checklist and Atlas of Taxonomy, Synonymy, Distribution, and Conservation Status (8th Ed.). In: Rhodin AGJ, JB Iversion, PP van Dijk, RA Saumure, KA Buhlmann, PCH Pritchard and RA Mittermeier (Eds,), Conservation Biology of Freshwater Turtles and Tortoises: A Compilation Project of the IUCN/SSC Tortoise and Freshwater Turtle Specialist Group. Chelonian Res. Monogr. 7: 1-292.

2. Praschag P, R Ghose and F Wollinger 2008. Field survey for the river terrapin (Batagur baska) in East India and Bangladesh. TSA, Turtle Survival Alliance Newsletter, August, pp. 30.

3. Praschag P, RS Sommer, C Mccarthy, R Gemel, and U Fritz 2008. Naming one of the world's rarest chelonians, the southern Batagur. Zootaxa 1758: 61-68.

4. Praschag, P., Singh, S. 2019. Batagur baska. The IUCN Red List of Threatened Species 2019. International Union for the Conservation of Nature. http://www.IUCN.org.

5. Moll EO, K Platt, SG Platt, P Prashag and PPV Dijk 2009. Batagur baska- Northern River Terrapin. In: Rhodin, AGJ, JB Iverson, PP. van Dijk, RA Saumure, KA Buhlmann, PCH Pritchard and RA Mittermeier (Eds,), Conservation Biology of Freshwater Turtles and Tortoises: A compilation project of the IUCN/ Tortoise and Turtle Specialist Group. Chelonian Res. Monogr. 5: 1-10.

6. Weissenbacher A, D Preininger, R Ghosh, AGJ Morshed and P Praschag 2015. Conservation breeding of the Northern river terrapin Batagur baska at the Vienna Zoo, Austria, and in Bangladesh. Int. Zoo Yearb 49: 31-41.

7. Morshed AGJ and I Sobhan 2014. Captive Breeding of the River Terrapin- Batagur baska (Gray 1830) in Bangladesh. In: Proc. of the Int. Symp. on River Biodiversity: GangesBrahmaputra-Meghna River System. Dhaka, Bangladesh, pp. 164-173. 
8. Reza AA. 2005. Current status of river terrapin, Batagur baska in Bangladesh. Unpublished report. Department of Zoology, Jahangirnagar University, Dhaka, Bangladesh, pp. 12.

9. Moll EO1997. Effects of habitat alteration on river turtles of tropical Asia with emphasis on sand mining and dams. In: Proc. of the Conservation, restoration and management of tortoises and turtles, New York Turtle and Tortoise Society, New York, USA, pp. 37-41.

10. Pandit PK 2013. Captive breeding of Batagur baska- a critically endangered species in Sundarbans tiger reserve, West Bengal, India. In: Naewboonnien, J (Eds,), Food and Agriculture Organization of the United Nations regional office for Asia and the pacific, Tigerpaper, Regional Quarterly Bulletin on Wildlife and National Parks Management, Bangkok, Thailand, pp. 1-6.

11. Behera S, AK Panda and S Nayak 2019. Status survey of Batagur baska and Pelochelys cantorii in the state of Odisha, east coast of India. Testudo 9: 36-46.

12. Platt K, SG Platt, K Thirakhupt and TR Rainwater 2008. Recent records and conservation status of the critically endangered mangrove terrapin, Batagur baska, in Myanmar. Chelonian Conserv. Biol. 7(2): 261-265.

13. Rashid SMA and MH Khan 2000. Trade and Conservation Status of Freshwater Turtles and Tortoises in Bangladesh. In: Asian Turtle Trade: Proc. of a Workshop on Conservation and Trade of Freshwater Turtles and Tortoises in Asia, Lunenburg, USA. Chelonian Res. Monogr. 2: 77-85.

14. Das I 1997. Conservation of tropical Asia's most threatened turtles. In: Proc. on the Conservation, restoration and management of tortoises and turtle. New York Turtle and Tortoise Society, New York, USA, pp. 295-301.

15. Rhodin, AJ, CB Stanford, PP van Dijk, C Eisemberg, L Luiselli, RA Mittermeier, R Hudson, BD Horne, EV Goode, G Kuchling. et al. 2018. Global conservation status of turtles and tortoises (Order Testudines). Chelonian Conserv. Biol. 17: 135-161.

16. Spitzweg C, P Praschag, D Shannon and F Uwe 2018. Conservation genetics of the northern river terrapin (Batagur baska) breeding project using a microsatellite marker system. Salamandra 54(1): 63-70.

17. Blanco S, JL Behler, and F Ksotel 1991. Propagation of the Batagurine turtles Batagur baska and Callagur borneoensis at the Bronx Zoo. In: Proc. 1st Int. Symp. on Turtles \& Tortoises; Conservation and Captive Husbandry, Austria, pp. 63-65.

18. Bhupathy S 1995. Status and distribution of the river terrapin Batagur baska in the Sundarbans of India. Final Project Report to the Salim Ali Center for Ornithology and Natural History, Coimbathore, India, pp. 37.

19. Rashid SMA and IR Swingland 1997. On the ecology of some freshwater turtles in Bangladesh. In: Proc. on the Conservation, restoration and management of tortoises and turtle, New York Turtle and Tortoise Society, New York, USA, pp. 225-242.

20. Miller JD and SA Dinkelacker. 2008. Reproductive structures and strategies of turtles. In: Wyneken, J, JH Godfrey and V Bels (Eds,), Biology of Turtles, From Structures to Strategies of Life, Boca Raton, FL: CRC Press, pp. 225-278.

21. Anderson J 1879. Anatomical and zoological researches: comprising an account of the zoological results of the two expeditions to western Yunnan in 1868 and 1875. London. 1: 985.

22. Duli NB 2009. Morphometric and genetic variability of river terrapin, (Batagur baska) and painted terrapin, (Batagur borneoensis). Unpublished M.Sc. Thesis. University of Science Malaysia, George Town, Malaysia, pp. 45. 
23. Sadat N. 2016. Study on the breeding biology of critically endangered estuarine terrapin Batagur baska (Gray, 1830) in a conservation breeding facility of Bangladesh. Unpublished MS thesis. Department of Zoology, Jagannath University, pp. 53.

24. Maxwell FD 1911. Reports on inland and sea fisheries in Thongwa, Myaungmya, and Bassein districts and the turtle-banks of Irrawaddy Division, Rangoon, Government Printing Office, Rangoon, pp. 57.

25. Daniel JC 2002. The book of Indian reptiles and amphibians, Bombay Natural History Society. Oxford University Press, Mumbai Delhi Caltutta Chennai, India.

26. Sanyal P and S Seth 1992. Rare terrapin (Batagur baska) breeding in Bengal. Tiger Paper 19(4): 10-11.

27. Moll EO 1990. Status and management of river terrapin (Batagur baska) in tropical Asia. Unpublished report of project WWF3901/ Asia to World Wide Fund for Nature, Gland, Switzerland, pp. 37.

28. Moll EO 1979. Reproductive cycles and adaptations. In: Harless, M, and H Morlock (Eds,), Turtles: Perspectives and Research. John Wiley and Sons, New York, pp. 305-331.

29. Godfray HCJ, L Partridge and PH Harvey1991. Clutch size. Annu. Rev. Ecol. Evol. Syst. 22: 409-429.

30. Ghosh A and NR Mandal 1990. Studies on nesting and artificial hatching of endangered river terrapin, Batagur baska (Gray) in Sundarbans Tiger reserve, West Bengal. Bombay Nat. Hist. Soc.87: 50-52.

31. Moll EO 1980. Natural history of the river terrapin, Batagur baska (Gray) in Malaysia. Malays. J. Sci. 6: 23-62.

(Manuscript received on 6 May, 2021; accepted on 25 November, 2021) 